\title{
IDENTIFICAÇÃO DE REGIÕES PLUVIOMETRICAMENTE HOMOGÊNEAS NO ESTADO DO RIO DE JANEIRO, UTILIZANDO-SE VALORES MENSAIS.
}

\author{
ROMISIO GERALDO BOUHID ANDRÉ ${ }^{1}$, VALDO DA SILVA MARQUES ${ }^{2}$, FRANCISCA MARIA \\ ALVES PINHEIRO ${ }^{2}$ e ANTONIO SERGIO FERRAUDO ${ }^{3}$
}

\author{
${ }^{1}$ Instituto Nacional de Meteorologia - INMET/MAPA, \\ ${ }^{2}$ Laboratório de Meteorologia -LAMET/CCT/UENF \\ ${ }^{3}$ Depto. de Ciências Exatas - FCAV/UNESP \\ romisio.andre@inmet.gov.br
}

Recebido Junho 2007 - Aceito Setembro 2008

\begin{abstract}
RESUMO
O objetivo deste trabalho é dar uma contribuição ao estudo das condições climáticas do Estado do Rio de Janeiro, visando a uma melhor Classificação Climática por meio da identificação de regiões homogêneas em precipitação. Para isto foram utilizadas médias mensais da precipitação de 48 estações meteorológicas, em um período de 30 anos (1971-2000). A análise hierárquica de agrupamento, a orografia e a proximidade do mar, mostraram que o Estado do Rio de Janeiro pode ser dividido, quanto à precipitação, em seis regiões pluviometricamente homogêneas o que possibilitou classificar as estações meteorológicas pelo método de classificação não hierárquica $k$-means. A região norte do Estado, com precipitações anuais em torno de $870 \mathrm{~mm}$ é a mais seca, e a região da encosta sul da Serra do Mar, com $2020 \mathrm{~mm}$, é a mais chuvosa. Mas, em ambas as regiões, os valores da precipitação da estação chuvosa representam em torno de $70 \%$ dos totais anuais.
\end{abstract}

Palavras-chave: regiões homogêneas, análise de agrupamento, precipitação mensal

\begin{abstract}
IDENTIFICATION OF HOMOGENEOUS PRECIPITATION REGIONS IN THE STATE OF RIO DE JANEIRO USING MONTHLY MEANS.

The aim of this work is to give a contribution to the study of climatic conditions for Rio de Janeiro State towards a better Climatic Classification by identifying homogeneous precipitation regions. Monthly mean rainfall for a period of thirty years (1971-2000), from 48 meteorological stations, were used. Cluster hierarchical analysis, orography and proximity to the ocean showed that Rio de Janeiro State could be divided into six homogeneous regions according to its rainfall distribution, which allowed the classification of meteorological stations by nonhierarchical $K$-means method. The north region of the State is the driest one, with annual rainfall around $870 \mathrm{~mm}$. The south hillside of Serra do Mar is the wettest. In both regions, the precipitation during the rainy season represents around $70 \%$ of the total annual rainfall.
\end{abstract}

Keywords: homogeneous regions, cluster analysis, monthly rainfall

\section{INTRODUÇÃO}

O Estado do Rio de Janeiro, com cerca de 40 mil quilômetros quadrados, embora se situe na orla litorânea da costa leste do território brasileiro, apresenta diferentes padrões climáticos. A disposição das serras do Mar e da Mantiqueira apresenta-se quase perpendicular ao escoamento médio da baixa troposfera, que associado às perturbações extratropicais, provoca um aumento considerável da precipitação a barlavento das montanhas, quando comparado com as mesmas situações atmosféricas nas regiões do Vale do Paraíba e da baixada litorânea. O conhecimento dos elementos de clima dessas regiões é uma importante ferramenta para a previsão de tempo em mesoescala e para auxiliar projetos agrícolas e industriais. Portanto, faz-se necessária a realização de estudos que visem à adoção de uma nova classificação climática, que leve em conta a variabilidade dos diversos elementos de clima ocorrida nos últimos anos. Para a compreensão dos processos climatológicos de uma região torna-se necessário um prévio conhecimento de seus diversos fatores, alguns de ordem estática, outros de natureza 
dinâmica, mas todos atuando simultaneamente. Este trabalho tem o objetivo de estabelecer as regiões pluviometricamente homogêneas utilizando-se análise hierárquica e não hierárquica de agrupamento, com base em precipitações médias mensais.

\section{CLIMA E OROGRAFIA}

O mapa da Figura 1 mostra a distribuição média anual de chuvas para o estado do Rio de Janeiro, no período 19712000. Embora nas regiões serranas e na parte sul do Estado as precipitações sejam elevadas, registram-se baixos índices pluviométricos nas regiões norte, noroeste e na região dos Lagos. Nota-se, no mapa da Figura 1, que nas regiões mencionadas o índice pluviométrico varia entre $750 \mathrm{~mm}$ a $1250 \mathrm{~mm}$ anuais. No decorrer do ano, a distribuição de chuvas mostra que a maior parte da precipitação ocorre no período que vai de outubro a março. Pelas classificações climáticas disponíveis (ex. Centro de Informações e Dados do Rio de Janeiro, 1999), parte das regiões norte e noroeste é classificada como semi-úmida e parte, como seca. Entretanto há indícios de que esteja se verificando aí um processo visível de diminuição do total pluviométrico nos últimos 40 anos, com implicações negativas nas atividades dependentes dos recursos hídricos dessas regiões (Marques et al., 2001).

A topografia do Estado (Fig. 2) tem uma influência marcante no regime de precipitação. Há extensas áreas próximas ao nível do mar, como a baixada litorânea e a região norte do Estado, e áreas montanhosas com altitudes acima de 1500 metros. Estas configurações orográficas influenciam de forma marcante a distribuição espacial da precipitação nessa área geográfica.

\section{REVISÃO DA LITERATURA}

Estudos da classificação de regiões pluviometricamente homogêneas foram realizados em diferentes áreas do território brasileiro, usando metodologias semelhantes à proposta neste artigo. A Tabela 1 sintetiza os principais trabalhos sobre o tema proposto.

\section{MATERIAL E MÉTODOS}

Foram utilizadas médias mensais da precipitação de 48 estações meteorológicas, período 1971-2000, das redes do Instituto Nacional de Meteorologia - INMET e da Agência Nacional de Águas - ANA, relativas ao território do Estado do Rio de Janeiro.

Para maior confiabilidade nos resultados foram consideradas apenas localidades contendo séries históricas de precipitação de 30 anos, o que acarretou a não uniformidade na distribuição espacial das estações, com certas falhas no centrosul e na região dos Lagos (Figura 3). A avaliação da estrutura

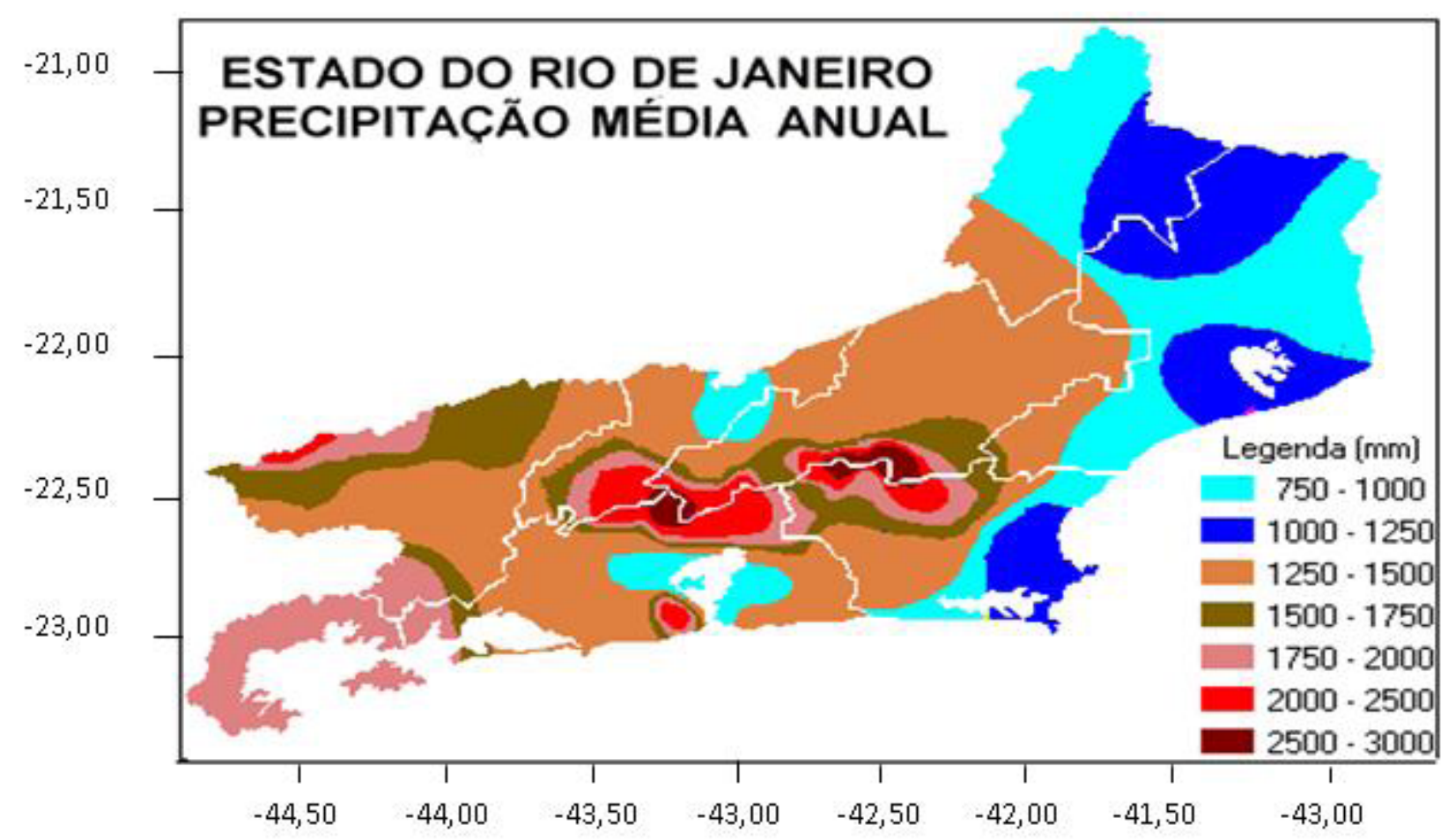

Figura 1 - Distribuição de chuvas anuais no Estado do Rio de Janeiro

FONTE: SIMERJ 


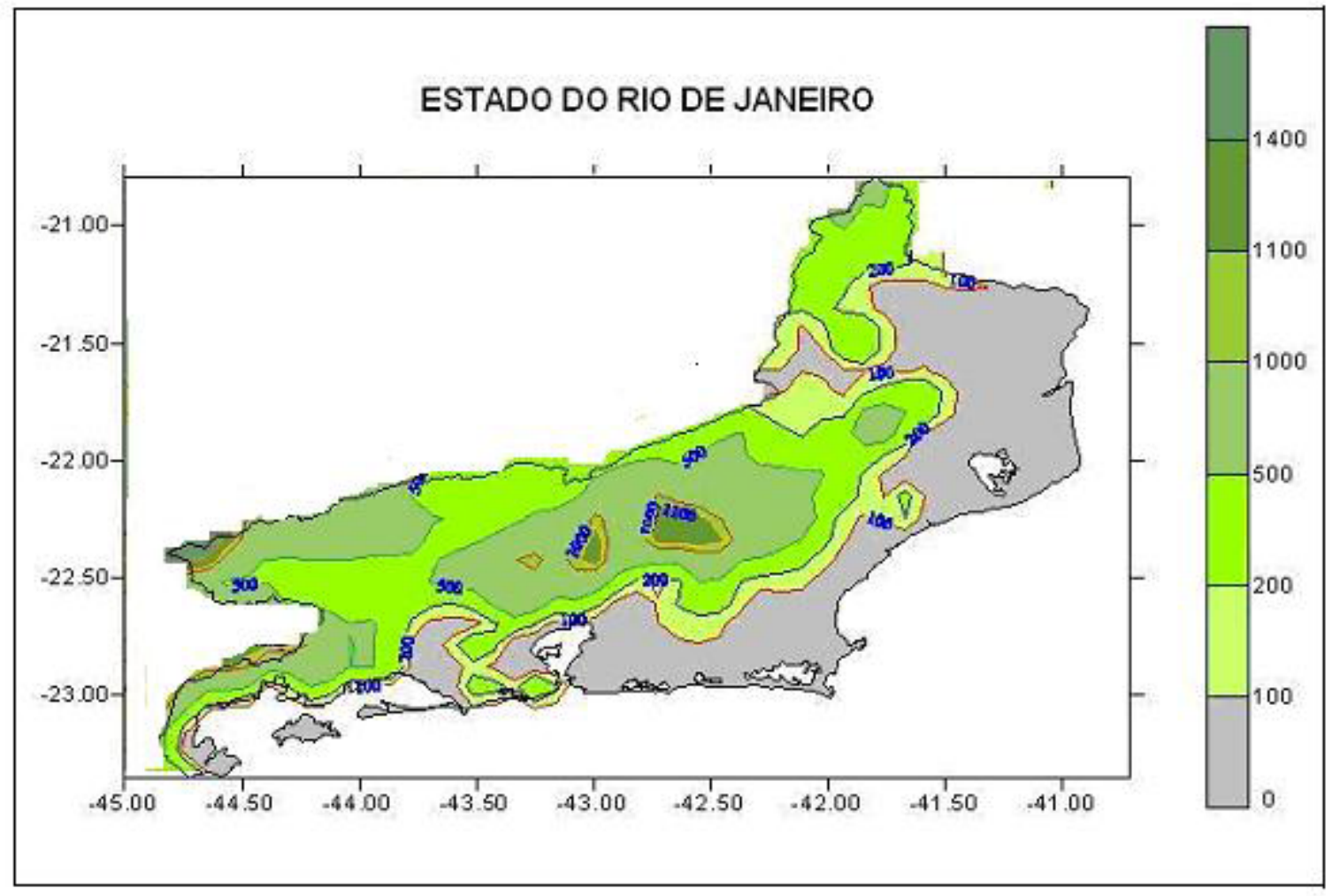

Figura 2 - Mapa topográfico do Estado do Rio de Janeiro.

de grupos contida nos dados foi feita pela análise hierárquica de agrupamento, adotando-se como medida de semelhança a distância euclidiana e como algoritmo de agrupamento o método de Ward (Wilks, 2006). A partir do número de grupos adotados, a estratificação das estações meteorológicas foi realizada utilizando-se análise não hierárquica de agrupamento, um método não supervisionado conhecido como K-means (Wilks, 2006), que busca agrupar as unidades experimentais segundo a semelhança entre elas, aqui representadas pelas estações meteorológicas. A semelhança entre as estações foi medida pela distância euclidiana entre cada unidade experimental e o centróide do grupo. A cada classificação de uma unidade experimental em um grupo, o centróide desse grupo é refinado pela média dos valores de cada atributo (Hair, et.al. 2005). Os processamentos das análises foram feitos no software Statistica, versão 7.0 (Statsoft., 2004) no Departamento de Ciências Exatas da Faculdade de Ciências Agrárias e Veterinárias, Campus de Jaboticabal -UNESP.

\section{RESULTADOS E DISCUSSÃO}

Os resultados encontrados com a aplicação da metodologia adotada e levando-se em conta a orografia e a proximidade do mar (Fig. 2), mostram que a melhor estratificação obtida foi a composta por seis regiões homogêneas para a distribuição espacial da precipitação no Estado. Na Tabela 3, estão descritos a precipitação, desvio padrão e coeficiente de variação das estações meteorológicas para as seis regiões consideradas na estratificação.

A Figura 3 mostra a distribuição espacial das 6 regiões homogêneas para o Estado do Rio de Janeiro. A região 1, compreendendo a encosta sul da Serra do Mar e parte da Serra da Mantiqueira, apresenta precipitação média anual variando de 2126,29 a $2605,86 \mathrm{~mm}$ e desvio padrão entre $81,57 \mathrm{e}$ $145,79 \mathrm{~mm}$. A região 2 engloba o vale do Paraíba, e possui precipitação média variando de 1431,43 a 1771,32 mm e desvio padrão entre 79,44 e 104,07 mm. A região 3, composta pela região Serrana do Estado, tem precipitação média variando de 1203,03 a $1532,16 \mathrm{~mm}$, com desvio padrão entre 72,29 e $86,34 \mathrm{~mm}$. A região 4 corresponde à encosta da Serra do Mar e região Sul Fluminense, com precipitação média variando de 1804,62 a 2202,03 mm e desvio padrão entre 73,27 e 94,00 $\mathrm{mm}$. A região 5, situada no Noroeste do Estado, apresenta precipitação média variando de 1002,96 a 1210,47 mm, com desvio padrão entre 47,27 e 72,04 mm. A região 6 compreende o Norte do Estado com precipitação média variando de 766,54 a $945,73 \mathrm{~mm}$ e desvio padrão entre 25,49 e $50,71 \mathrm{~mm}$. 
Tabela 1 - Estudos realizados em diferentes partes do Brasil com os métodos usados nesta pesquisa.

\begin{tabular}{|c|c|c|c|c|}
\hline Estudo realizado & $\begin{array}{l}\text { Local do } \\
\text { estudo }\end{array}$ & $\begin{array}{l}N^{0} \text { de } \\
\text { estações }\end{array}$ & $\begin{array}{c}\text { Dados e período } \\
\text { Utilizados }\end{array}$ & Autores \\
\hline $\begin{array}{l}\text { Determinaçâo de regiôes } \\
\text { pluviometricamente } \\
\text { homogêtleas }\end{array}$ & Paraiba & 65 & $\begin{array}{l}\text { Decendiais médios } \\
1930-1981\end{array}$ & $\begin{array}{l}\text { Braga e Silva } \\
(1990)\end{array}$ \\
\hline $\begin{array}{l}\text { Identificação de regiôes } \\
\text { pluviometricamnente } \\
\text { homogêneas. }\end{array}$ & \begin{tabular}{|c|} 
Rio Grande do \\
Norte
\end{tabular} & 59 & $\begin{array}{l}\text { Decendiais médios } \\
30 \text { anos }\end{array}$ & Braga (1992) \\
\hline $\begin{array}{l}\text { Identificação de regiōes } \\
\text { pluviometricamente } \\
\text { homogêneas }\end{array}$ & $\begin{array}{c}\text { Rio Grande do } \\
\text { Sul }\end{array}$ & 41 & $\begin{array}{l}\text { Médias mensais } \\
1931-1960\end{array}$ & $\begin{array}{l}\text { Becker et al. } \\
(1992)\end{array}$ \\
\hline $\begin{array}{l}\text { Identificação de regiôes } \\
\text { pluviometricamente } \\
\text { homogêneas. }\end{array}$ & Pernambuco & 56 & $\begin{array}{l}\text { Decendiais médios } \\
30 \text { anlos }\end{array}$ & $\begin{array}{l}\text { Braga e } \\
\text { Targitio (1994) }\end{array}$ \\
\hline $\begin{array}{l}\text { Determinação de regiōes } \\
\text { climatologicamente } \\
\text { homogêneas. }\end{array}$ & Ceará & 84 & $\begin{array}{l}\text { Estação chuvosa } \\
1913-1983\end{array}$ & $\begin{array}{l}\text { Rodrigues et } \\
\text { al.(1996) }\end{array}$ \\
\hline $\begin{array}{l}\text { Determinação de regiôes } \\
\text { climatologicamente } \\
\text { homogêtleas. }\end{array}$ & $\begin{array}{l}\text { Tabuleiros e } \\
\text { baixadas } \\
\text { litorâneas do } \\
\text { NE brasileiro } \\
\end{array}$ & 127 & $\begin{array}{l}\text { Médias mensais } \\
20 \text { anos }\end{array}$ & $\begin{array}{l}\text { Silva et } \\
\text { al.(1996a) }\end{array}$ \\
\hline $\begin{array}{l}\text { Identificação de sub-regiōes } \\
\text { homogêtneas com relação ao } \\
\text { ciclo anual da precipitação } \\
\text { decendial e variaçoses devidas } \\
\text { ao ENOS. }\end{array}$ & Paraiba & 68 & $\begin{array}{l}\text { Decendiais médios } \\
1930-1993\end{array}$ & $\begin{array}{l}\text { Silva et } \\
\text { al.(1996b) }\end{array}$ \\
\hline $\begin{array}{l}\text { Análise de chuvas máximas e } \\
\text { médias. }\end{array}$ & Alagoas & 60 & $\begin{array}{l}\text { Médias mensais } \\
1912-1985 \\
\end{array}$ & $\begin{array}{l}\text { Souza et al. } \\
(1992)\end{array}$ \\
\hline $\begin{array}{l}\text { Microrregiőes de precipitaçồes } \\
\text { homogêneas. }\end{array}$ & \begin{tabular}{|c|} 
Rio Grande do \\
Norte
\end{tabular} & 59 & \begin{tabular}{|l|} 
Estação chuvosa \\
$1910-1990$ \\
\end{tabular} & $\begin{array}{l}\text { Lopes et al. } \\
(1996)\end{array}$ \\
\hline $\begin{array}{l}\text { Determinação de regiôes } \\
\text { homogêneas de precipitação e } \\
\text { vazão com observaçôes } \\
\text { convencionais e telemétricas. }\end{array}$ & Paraná & $\begin{array}{l}48^{*} \\
78\end{array}$ & $\begin{array}{l}\text { Médias mensais e } \\
\text { totais anuais } \\
10 \text { anos }\end{array}$ & $\begin{array}{l}\text { Marcelini et al. } \\
(1996)\end{array}$ \\
\hline $\begin{array}{l}\text { Determinação de datas de } \\
\text { início e final da estação } \\
\text { chuvosa para regiồes } \\
\text { homogêtleas }\end{array}$ & Paraná & 89 & $\begin{array}{l}\text { Totais mensais e } \\
\text { qüinqüídios } \\
1967-1992\end{array}$ & $\begin{array}{l}\text { Freitas e } \\
\text { Grimm (1998) }\end{array}$ \\
\hline $\begin{array}{l}\text { Identificaçấo de sub-regiôes } \\
\text { homogêtreas ent relação ao } \\
\text { ciclo total anual da precipitação } \\
\text { decendial }\end{array}$ & Bahia & 140 & $\begin{array}{l}\text { Decendiais médios } \\
30 \text { anıs }\end{array}$ & $\begin{array}{l}\text { Braga et al. } \\
\text { (1998) }\end{array}$ \\
\hline $\begin{array}{l}\text { Identificaçấo de sub-regiōes } \\
\text { pluviométricas (uso do método } \\
\text { de classificação de LUND, } \\
\text { 1963). }\end{array}$ & $\begin{array}{c}\text { Rio Grande do } \\
\text { Sul e Santa } \\
\text { Catarina }\end{array}$ & 13 & $\begin{array}{l}\text { Médias mensais } \\
1911-1995\end{array}$ & $\begin{array}{l}\text { Khan e Kim } \\
\text { (1998) }\end{array}$ \\
\hline
\end{tabular}


Tabela 2 - Estações meteorológicas consideradas na estratificação.

\begin{tabular}{|c|c|c|c|}
\hline Estação Meteorológica & Latitude (S) & Longitude (0) & Altitude (m) \\
\hline Aldeia & $-21: 57: 09$ & $-42: 21: 21$ & 376 \\
\hline Areal (Granja Gabi) & $-22: 14: 31$ & $-43: 06: 16$ & 450 \\
\hline Barra Alegre & $-22: 14: 08$ & $-42: 17: 09$ & 650 \\
\hline Bom Jardim & $-22: 09: 24$ & $-42: 24: 58$ & 530 \\
\hline Campos & $-21: 44: 00$ & $-41: 19: 00$ & 11 \\
\hline Cardoso Moreira & $-21: 29: 31$ & $-41: 36: 49$ & 20 \\
\hline Dois Rios & $-21: 38: 36$ & $-41: 51: 31$ & 50 \\
\hline Farol de São Tomé & $-22: 02: 33$ & $-41: 03: 20$ & 2 \\
\hline Fazenda Agulhas Negras & $-22: 20: 21$ & $-44: 35: 26$ & 1460 \\
\hline Fazenda do Carmo & $-22: 26: 17$ & $-42: 46: 03$ & 40 \\
\hline Fazenda Mendes & $-22: 17: 09$ & $-42: 39: 36$ & 1010 \\
\hline Fazenda São João & $-22: 23: 22$ & $-42: 30: 00$ & 1010 \\
\hline Fazenda São Joaquim & $-22: 26: 28$ & $-42: 37: 19$ & 275 \\
\hline Fazenda Sobradinho & $-22: 12: 04$ & $-42: 54: 00$ & 650 \\
\hline Fumaça & $-22: 17: 51$ & $-44: 18: 38$ & 720 \\
\hline Gaviões & $-22: 32: 56$ & $-42: 32: 46$ & 1620 \\
\hline Itamarati & $-22: 29: 07$ & $-43: 08: 57$ & 1085 \\
\hline Itaperuna & $-21: 12: 19$ & $-41: 54: 24$ & 110 \\
\hline lapuíba & $-22: 33: 33$ & $-42: 41: 56$ & 50 \\
\hline Leitão da Cunha & $-22: 02: 34$ & $-42: 02: 39$ & 425 \\
\hline Macabuzinho & $-22: 04: 39$ & $-41: 42: 32$ & 19 \\
\hline Manuel Duarte (PCD) & $-22: 05: 09$ & $-43: 33: 24$ & 396 \\
\hline Maria Mendonça & $-22: 11: 11$ & $-42: 09: 49$ & 800 \\
\hline Morelli & $-22: 12: 03$ & $-43: 01: 37$ & 600 \\
\hline Nossa Senhora do Amparo & $-22: 23: 08$ & $-44: 06: 27$ & 400 \\
\hline Patrimônio & $-23: 13: 19$ & $-44: 45: 48$ & 90 \\
\hline Pedro do Rio & $-22: 19: 57$ & $-43: 08: 10$ & 645 \\
\hline Piller & $-22: 24: 17$ & $-42: 20: 21$ & 670 \\
\hline Ponte do Souza & $-22: 16: 14$ & $-44: 23: 03$ & 950 \\
\hline Porciúncula & $-20: 57: 48$ & $-42: 02: 14$ & 188 \\
\hline Quartéis & $-22: 27: 47$ & $-42: 18: 43$ & 58 \\
\hline Ribeirão de São Joaquim & $-22: 28: 27$ & $-44: 13: 44$ & 620 \\
\hline Rio da Cidade & $-22: 26: 17$ & $-43: 10: 13$ & 704 \\
\hline Rio Dourado & $-22: 28: 33$ & $-42: 05: 07$ & 12 \\
\hline Santa Isabel do Rio Preto & $-22: 13: 52$ & $-44: 03: 53$ & 544 \\
\hline Santo Antonio de Pádua & $-21: 32: 31$ & $-42: 10: 57$ & 70 \\
\hline São Fidelis & $-21: 38: 43$ & $-41: 45: 08$ & 10 \\
\hline São Francisco Paula-Cacimbas & $-21: 28: 58$ & $-41: 06: 12$ & 15 \\
\hline São Roque & $-23: 04: 20$ & $-44: 41: 53$ & 0 \\
\hline Taboas & $-22: 12: 31$ & $-43: 37: 24$ & 444 \\
\hline Teodoro de Oliveira & $-22: 22: 44$ & $-42: 33: 15$ & 0 \\
\hline Três Irmãos & $-21: 37: 36$ & $-41: 53: 09$ & 42 \\
\hline Usina Quissamã & $-22: 06: 22$ & $-41: 28: 16$ & 15 \\
\hline Valença & $-22: 13: 08$ & $-43: 42: 13$ & 549 \\
\hline Vargem Alta & $-22: 18: 03$ & $-42: 24: 00$ & 1100 \\
\hline Vargem Grande & $-22: 16: 36$ & $-42: 30: 08$ & 680 \\
\hline Visconde de Imbé & $-22: 04: 04$ & $-42: 09: 36$ & 334 \\
\hline Volta Redonda & $-22: 30: 04$ & $-44: 05: 31$ & 360 \\
\hline
\end{tabular}


As curvas apresentadas na Figura 4 mostram as distribuições mensais da precipitação média de cada região homogênea determinada pelo método K-means. Por meio dessas curvas é possível comparar as regiões, bem como avaliar onde há maior ou menor variabilidade da média. Observa-se que durante o período chuvoso (outubro a março) há uma considerável dispersão entre os valores mensais das seis regiões homogêneas. Entretanto, nos três meses mais secos (junho, julho, agosto) somente as regiões 1 e 4 apresentam variações consideráveis em relação às demais.

A Tabela 4 mostra a contribuição da precipitação para as estações chuvosa (outubro a março) e seca (abril a setembro), em cada região. Nela verifica-se a maior precipitação das regiões 1 e 4 em relação às demais, tanto na estação chuvosa (precipitação média acima de $2000 \mathrm{~mm}$ ) como na estação seca (com precipitação média acima de $600 \mathrm{~mm}$ ).

A precipitação na estação chuvosa na região 1 é $73 \%$ do total anual e, na região 4 , é de $69 \%$. O principal conjunto de estações dessas regiões se localiza na encosta sul da Serra do Mar, que por razões já explicadas, favorecem o regime de precipitações elevadas. O segundo conjunto representado pelas estações localizadas no Sul Fluminense tem uma explicação diferente, pois neste caso, a alta precipitação se explica pela conformação da costa e a influência sofrida pela alta umidade proveniente do oceano na ocasião de escoamento de sudoeste, durante as penetrações frontais.
As regiões 5 e 6 são aquelas com menores valores, tanto na estação chuvosa como na seca, já que os valores anuais médios da precipitação ficaram entre 869 e 1110 mm. Na região 6 , a precipitação de verão representa apenas $69 \%$ do total anual e na região $5,78 \%$. Essas regiões se localizam no Norte e Noroeste do Estado, onde há uma grande baixada a sotavento da serra do Mar, favorecendo a compressão na baixa troposfera por ocasião das penetrações de escoamento de Sudoeste, que são os principais mecanismos de formação de chuva na região.

A região 2 apresenta-se com precipitação anual entre 1400 a 1800 mm. Essa região corresponde ao Vale do Paraíba, onde o regime de precipitação é governado pelas incursões frontais favorecidas pelos mecanismos de levantamento do ar na encosta da Serra da Mantiqueira, ocorrendo isso com predominância na estação chuvosa, que corresponde a $79 \%$ do total anual. Já na região 3 a precipitação anual varia entre 1200 a $1500 \mathrm{~mm}$. Essa é a região Serrana do Estado, onde o fator altitude tem grande importância na determinação do regime chuvoso, sendo um regime de chuvas de verão com cerca de $79 \%$ do total anual.

A maior variabilidade da precipitação média é claramente observada na época chuvosa, como pode se observar na Figura 4. Nos totais médios anuais (Tabela 3 ), verifica-se que as regiões 4 e 6 têm os menores valores do coeficiente de variação, abaixo de 5,0 para a maioria das estações, enquanto as regiões 2 e 3 apresentam os maiores valores (acima de 5,5).

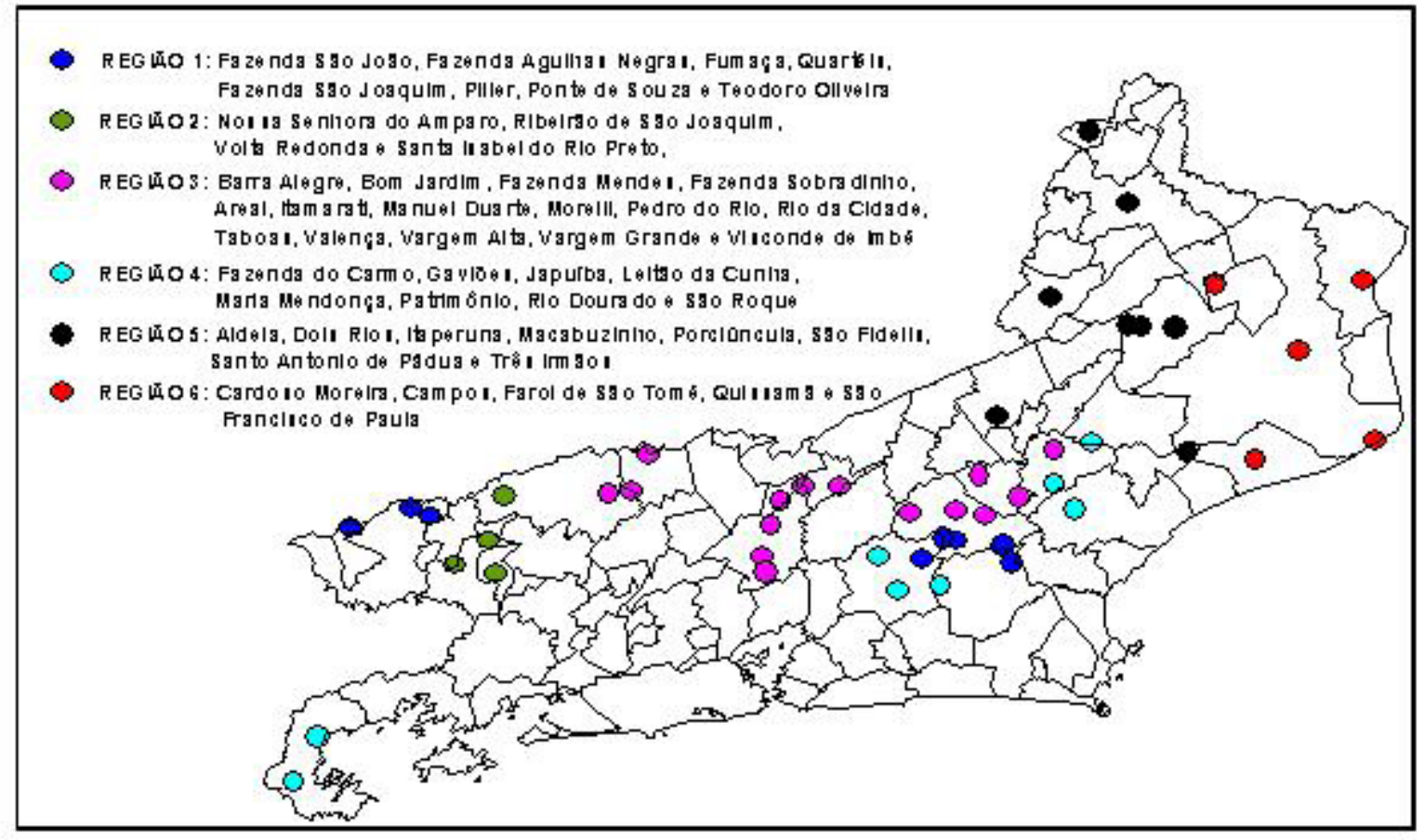

Figura 3 - Distribuição espacial das regiões contendo as respectivas estações pluviométricas do Estado do Rio de Janeiro. 
Tabela 3 - Valores médios anuais da precipitação, desvio padrão e coeficiente de variação das estações meteorológicas para as seis regiões consideradas na estratificação.

\begin{tabular}{|c|c|c|c|c|}
\hline REGIĨO & Estação meteorológica & $\begin{array}{l}\text { Precipitação } \\
\text { média (mm) }\end{array}$ & $\begin{array}{c}\text { Desvio } \\
\text { padrão }(\mathrm{mm})\end{array}$ & $\begin{array}{c}\text { Coeficiente de } \\
\text { variação }(\%)\end{array}$ \\
\hline $\mathrm{I}$ & Fazenda São João & 2213,15 & 120,48 & 5,44 \\
\hline $\mathrm{I}$ & Fazenda Agulhas Negras & 2450,98 & 145,79 & 5,95 \\
\hline I & Fazenda São Joaquim & 2605,86 & 81,57 & 3,13 \\
\hline $\mathrm{I}$ & Fumaça & 2203,95 & 143,46 & 6,51 \\
\hline $\mathrm{I}$ & Piller & 2268,01 & 98,09 & 4,32 \\
\hline $\mathrm{T}$ & Ponte de Souza & 2126,29 & 125,97 & 5,92 \\
\hline $\mathrm{T}$ & Quartéis & 2404,29 & 100,68 & 4,19 \\
\hline $\mathrm{I}$ & Teodoro Oliveira & 3122,52 & 104,95 & 3,36 \\
\hline II & N.S.Amparo & 1771,32 & 104,07 & 5,88 \\
\hline II & Rib.S.Joaquim & 1551,48 & 90,48 & 5,83 \\
\hline II & Sat.Isabel & 1632,08 & 97,94 & 6,00 \\
\hline II & V.Redonda & 1431,43 & 79,44 & 5,55 \\
\hline III & Areal & 1256,34 & 74,91 & 5,96 \\
\hline III & Barra Alegre & 1318,19 & 80,11 & 6,08 \\
\hline III & Bom Jardim & 1368,14 & 84,93 & 6,21 \\
\hline III & Fazenda Mendes & 1439,63 & 81,72 & 5,68 \\
\hline III & Fazenda Sobradinho & 1222,94 & 72,29 & 5,91 \\
\hline III & Itamarati & 1532,16 & 84,71 & 5,53 \\
\hline III & Manuel Duarte & 1204,41 & 73,10 & 6,07 \\
\hline III & Morelli & 1203,03 & 74,33 & 6,18 \\
\hline III & Pedro do Rio & 1274,24 & 74,46 & 5,84 \\
\hline III & Rio da Cidade & 1470,38 & 86,34 & 5,87 \\
\hline III & Taboas & 1229,84 & $\overline{74,14}$ & 6,03 \\
\hline III & Valença & 1222,10 & 74,33 & 6,08 \\
\hline III & Vargem Alta & 1463,32 & 85,70 & 5,86 \\
\hline III & Vargem Grande & 1375,13 & 84,66 & 6,16 \\
\hline III & Visconde de Imbé & 1381,62 & 85,73 & 6,21 \\
\hline IV & Fazenda do Carmo & 2084,13 & 92,24 & 4,43 \\
\hline $\mathrm{TV}$ & Gaviôes & 2125,45 & 94,00 & 4,42 \\
\hline IV & Japuíba & 1804,62 & 78,53 & 4,35 \\
\hline $\mathrm{IV}$ & Leitão da Cunha & 1912,48 & 74,30 & 3,89 \\
\hline $\mathrm{N}$ & Maria Mendonça & 1976,58 & 82,08 & 4,15 \\
\hline IV & Patrimônio & 2123,67 & 73,27 & 3,45 \\
\hline V & Rio Dourado & 1937,31 & 74,32 & 3,84 \\
\hline $\mathrm{N}$ & S.Roque & 2202,03 & 91,17 & 4,14 \\
\hline $\mathrm{V}$ & Aldeia & 1185,34 & 70,92 & 5,98 \\
\hline $\mathrm{V}$ & Dois Rios & 1002,96 & 57,33 & 5,72 \\
\hline $\mathrm{V}$ & Itaperuna & 1180,21 & 69,55 & 5,89 \\
\hline $\mathrm{V}$ & Macabuzinho & 1093,23 & 47,27 & 4,32 \\
\hline $\bar{V}$ & Porciúncula & 1210,47 & 72,04 & 5,95 \\
\hline $\bar{V}$ & S.A Pádua & 1146,52 & 67,84 & 5,92 \\
\hline V & S.Fidelis & 1006,22 & 57,30 & 5,69 \\
\hline V & Três Imãas & 1055,49 & 62,53 & 5,92 \\
\hline VI & C.Moreira & 921,31 & 50,71 & 5,50 \\
\hline$\overline{\mathrm{V} \mid}$ & Campos & 945,73 & 41,84 & 4,42 \\
\hline$\overline{\mathrm{Vl}}$ & F.S.Tomé & 766,54 & 25,49 & 3,33 \\
\hline$\overline{\mathrm{V}}$ & Quissamã & 918,31 & 36,31 & 3,95 \\
\hline$\overline{\mathrm{V} /}$ & S.F.Paula & 792,48 & 33,98 & 4,29 \\
\hline
\end{tabular}




\section{CONCLUSÕES:}

Os estudos aqui desenvolvidos mostram, pela primeira vez, que o Estado do Rio de Janeiro pode ser dividido em seis regiões pluviometricamente homogêneas com cerca de $70 \%$ a $80 \%$ das precipitações ocorrendo no verão e $20 \%$ a $30 \%$ no inverno. Embora a distribuição das estações, contendo séries de precipitações mensais com 30 anos, não tenha sido uniforme em todo o Estado, foi possível encontrar uma estratificação adequada da distribuição da precipitação, que representa uma contribuição importante para os trabalhos que estão sendo desenvolvidos pela equipe, para a elaboração de uma nova classificação climática para o Estado.

\section{REFERÊNCIAS BIBLIOGRÁFICAS}

BECKER, C.T., BRAGA, C.C., CEBAllos, J.C. Regionalização da precipitação e temperatura no estado do Rio Grande do Sul a partir de análise de agrupamento. In: CONGRESSO BRASILEIRO DE METEOROLOGIA, 7, São Paulo. Anais...Sociedade Brasileira de Meteorologia. v1.p 225-32, 1992.

BRAGA, C.C. Classificação de regiões pluviometricamente homogêneas através da análise multivariada. In: CONGRESSO BRASILEIRO DE METEOROLOGIA, 7, São Paulo. Anais...Sociedade Brasileira de Meteorologia. p.2341-43, 1992.

Tabela 4 - Contribuição da precipitação, nos períodos chuvoso e seco, para as diferentes regiões.

\begin{tabular}{|l|r|r|r|r|r|r|}
\hline & Região 1 & Região 2 & Região 3 & Região 4 & Região 5 & Região 6 \\
\hline Prec.amual & 2424,38 & 1596,57 & 1330,76 & 2020,78 & 1110,05 & 868,87 \\
\hline Per.chuvoso & 1772,17 & 1259,57 & 1056,35 & 1403,89 & 864,89 & 603,85 \\
\hline Per.seco & 652,21 & 337,00 & 274,42 & 616,89 & 245,16 & 265,03 \\
\hline$\%$ Per.chuvoso & 73 & 79 & 79 & 69 & 78 & 69 \\
\hline$\%$ Per.seco & 27 & 21 & 21 & 31 & 22 & 31 \\
\hline
\end{tabular}

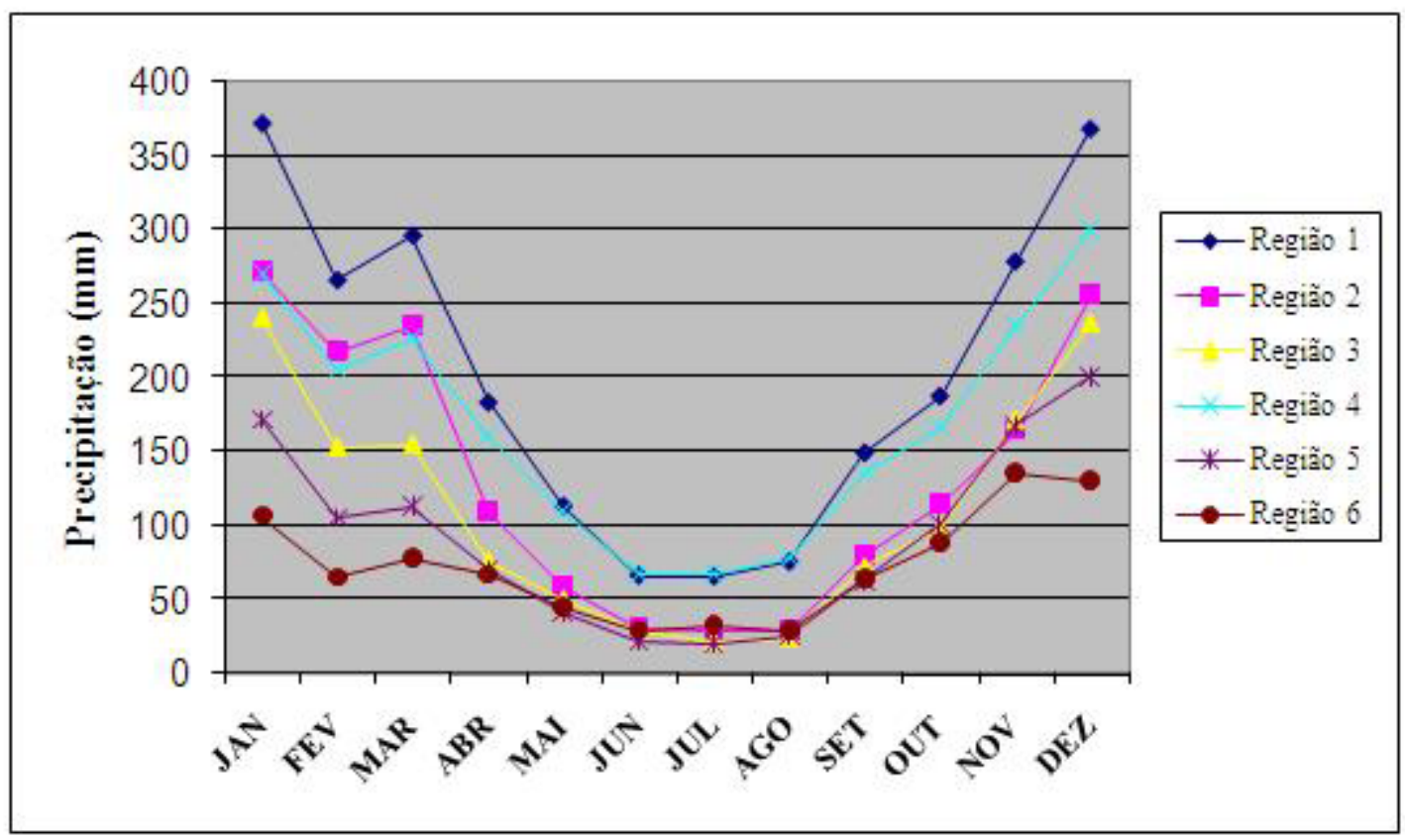

Figura 4 - Precipitação média mensal das seis regiões estratificadas. 
BRAGA, C.C., SILVA, B.B. Determinação de regiões pluviometricamente homogêneas no estado da Paraíba. In: CONGRESSO BRASILEIRO DE METEOROLOGIA, 6, Salvador - BA. Anais...Sociedade Brasileira de Meteorologia. p.200-205,1990.

BRAGA, C.C., TARGINO, A.C. L. Análise objetiva da distribuição pluviométrica no Estado de Pernambuco.In In: CONGRESSO BRASILEIRO DE METEOROLOGIA, 8, Congresso Latino Americano,2, Belo Horizonte - MG. Anais...:p.382-384,1994.

BRAGA, C.C., de MELO, M.L.D., MELO, E.C.S. Análise de agrupamento aplicada a distribuição da precipitação no Estado da Bahia. In: CONGRESSO BRASILEIRO DE METEOROLOGIA, 10, Brasília-DF. Anais... Sociedade Brasileira de Meteorologia. p.1857-62, 1998.

FREITAS, E.D. e GRIMM, A.M. Determinação de datas de início e fim da estação chuvosa para regiões homogêneas no Estado do Paraná. In: CONGRESSO BRASILEIRO DE METEOROLOGIA, 10, Brasília-DF, Anais...Sociedade Brasileira de Meteorologia.1998. CD-ROM.

HAIR Jr, J.F., ANDERSON, R.E, TATHAM, R.L., BLACK, W.C. Análise Multivariada de Dados. 5 ${ }^{a}$ ed. Porto Alegre: Bookman, 2005.

KHAN, V.M., KIM, I.S., SARAIVA, J.M. Análise de agrupamento pluviométriconosestados doRio GrandedoSule SantaCatarina. In: CONGRESSO BRASILEIRO DE METEOROLOGIA, 10, CONGRESSO LATIONAMARICANO E IBÉRICO DE METEOROLOGIA, 8., Brasília, D.F. Anais... Sociedade Brasileira de Meteorologia. 1998. CD-ROM.

LOPES, P.M.O., SILVA, B.B., RODRIGUES, M.F.G. Identificação de grupos pluviometricamente homogêneos no Estado do Rio Grande do Norte. In: CONGRESSO BRASILEIRO DE METEOROLOGIA, 9,Campos do Jordão-SP. Anais... Sociedade Brasileira de Meteorologia. p.272-274,1996.

LUND, J.A. Map-patern classification by statistical methods. J. App. Meteorology. v.2, n.1, p.56- 65, 1963.
MARCELINI, S.S., KAVISKI, E., MINE, M.R.M., KRUGER, C.M. Regiões homogêneas de precipitação e vazão para o Estado do Paraná. In: CONGRESSO BRASILEIRO DE METEOROLOGIA, 9,Campos do Jordão-SP. Anais... Sociedade Brasileira de Meteorologia p.241-243,1996.

MARQUES, V. S., ANDRÉ, R. G. B., SUCHAROV, E. C., PINHEIRO, F. M. A. Possíveis Modificações na Classificação Climática das Regiões Norte e Noroeste do Estado do Rio de Janeiro. Relatório SIMERJ, 15p. 2001.

RODRIGUES, M.F.G.,AZEVEDO, P.V., SILVA, B.B. Uso da classificação hierárquica na identificação de regiões pluviometricamente homogêneas no Estado do Ceará. In: CONGRESSO BRASILEIRO DE METEOROLOGIA, 9,Campos do Jordão-SP. Anais... Sociedade Brasileira de Meteorologia p. 275-276,1996.

SILVA, S.T., BRAGA, C.C., ARAGÃO, M.R.S. Influência do El Nino - Oscilação Sul na distribuição espacial e temporal da precipitação no Estado da Paraíba. In: CONGRESSO BRASILEIRO DE METEOROLOGIA, 9,Campos do Jordão-SP. Anais... Sociedade Brasileira de Meteorologia p. 236-239,1996.

SILVA, A.A.G., BRAGA, C.C., OLIVEIRA, L.S. Análise de agrupamento aplicada ao regime pluviométrico da costa leste e norte do Nordeste do Brasil. In: CONGRESSO BRASILEIRO DE METEOROLOGIA, 9,Campos do Jordão-SP. Anais... Sociedade Brasileira de Meteorologia p. 231-235, 1996.

SOUZA, J.L., de AMORIM, R.F.C., CARVALHO, S.M.R., PEREIRA, J.O., Curi, P.R.C. Agrupamento de estações pluviométricas do Estado de Alagoas, utilizando-se análise multivariada. Rev. Brasileira de Meteorologia, v. 7, n.2, p.603-12, 1992.

STATSOFT, Inc. (2004). STATISTICA (data analysis software system), version 7. www.statsoft.com..

WILKS, D. S. Statistical Methods in the Atmospheric Sciences. International Geophysics Series, Vol. 91, Elsevier, 627 p. 2006. 